\title{
Equality of Treatment for Hip Fracture Irrespective of Regional Differences in Socioeconomic Status: Analysis of Nationwide Hospital Claims Data in Japan
}

\author{
Shinichi Tomioka, ${ }^{1}$ Yoshihisa Fujino, ${ }^{2}$ Tomoki Nakaya, ${ }^{3}$ Makoto Ohtani, ${ }^{4}$ \\ Tatsuhiko Kubo ${ }^{2}$ and Shinya Matsuda ${ }^{1}$ \\ ${ }^{1}$ Department of Preventive Medicine and Community Health, University of Occupational and Environmental \\ Health, Kitakyushu, Fukuoka, Japan \\ ${ }^{2}$ Department of Environmental Epidemiology, University of Occupational and Environmental Health, Kitakyushu, \\ Fukuoka, Japan \\ ${ }^{3}$ Graduate School of Environmental Studies, Tohoku University, Sendai, Miyagi, Japan \\ ${ }^{4}$ Data Science Center for Occupational Health, University of Occupational and Environmental Health, Kitakyushu, \\ Fukuoka, Japan
}

\begin{abstract}
Despite the wide variety of international evidence on the relationship between the socioeconomic status (SES) and health outcomes, less is known about the association between SES and healthcare provider practices. We assessed whether patients with a closed hip fracture were treated differently by hospital physicians according to the SES of their residential areas in Japan. Hip fracture is a common cause of hospitalization among the elderly, but the relationship between SES and hip fracture treatment remains unknown in Japan. We employed the Diagnosis Procedure Combination (DPC) database from April 2011 to March 2014. SES of the patient's residential area was estimated using Census-derived areal deprivation index (ADI). We performed a cross-sectional study of national claims data and analyzed it using crossclassified multilevel models. We used two outcome measures: (i) whether the patient received an operation or was treated by watchful waiting; and (ii) number of waiting days until operation following admission. We identified 95,011 patients admitted to 1,050 hospitals. Of these, 85,480 patients underwent surgery. Low SES of residential areas was not correlated with the chance of undergoing surgery $(P=0.15)$ but was weakly correlated with longer waiting days (coefficient, $0.03 ; 95 \%$ confidence interval, -0.01 to $0.06 ; P=$ 0.08). The difference of waiting days between maximum (10.4) and minimum ADI (-4.0) was marginal (0.39 days). The results indicate the SES of patient's residential area does not affect the decision of surgical treatment for hip fracture and has ignorable impact on waiting days from hospital admission to surgery.
\end{abstract}

Keywords: disparity; hip fracture; residential area; socioeconomic status; surgical treatment Tohoku J. Exp. Med., 2019 March, 247 (3), 161-171. (C) 2019 Tohoku University Medical Press

\section{Introduction}

According to 2015 data, Japan has the longest average hospital stays, the largest number of hospital beds, the highest number of advanced diagnostic technologies (e.g., computed tomography scanners and magnetic resonance imaging machines), and the second most frequent doctor consultations per capita among Organization for Economic Co-operation and Development (OECD) countries (OECD 2017). The sharp increase in the aging population will impose serious financial difficulties on the Japanese healthcare system and its sustainability has been questioned. In these circumstances, patients who will most likely suffer are those with a lower socioeconomic status (SES), possibly due to such factors as unequal treatment by healthcare providers, despite the presence of universal health coverage and uniform Japanese health care system.

Unlike other developed nations, Japan is widely known for its homogeneity, as evidenced by United Nations (UN) statistics showing a proportion of international migrants of $1.8 \%$ in 2017 compared to an average of $14.1 \%$ in the high-income countries overall (UN 2017). Despite having the third-largest gross domestic product (GDP) and a highly homogenous population, large differences in areal SES between affluent and deprived areas were reported by government statistics up until 1995 (Management and Coordination Agency 1995). No large-scale investigation has since been conducted due to concerns that those labeled

Received December 7, 2018; revised and accepted February 18, 2019. Published online March 13, 2019; doi: 10.1620/tjem.247.161. Correspondence: Shinichi Tomioka, Department of Preventive Medicine and Community Health, University of Occupational and Environmental Health, 1-1 Iseigaoka, Yahatanishi-ku, Kitakyushu, Fukuoka 807-8555, Japan.

e-mail: stomioka@med.uoeh-u.ac.jp 
as "deprived" may face discrimination, and it remains unclear whether people residing in different SES areas are treated differently when accessing healthcare.

Despite the wide variety of international evidence on the relationship between SES and health outcomes (e.g., mortality) (Kawachi et al. 1997; Pickett and Pearl 2001; Kondo et al. 2009), less is known about the association between SES and healthcare provider practices. Hip fractures are one of the most common causes of hospitalization among the elderly and exert considerable impact on the patient as well as the healthcare system. Some studies from overseas countries have explored the associations between SES and hip fracture treatment (Shortt and Shaw 2003; Löfvendahl et al. 2005; Barone et al. 2009; Fanuele et al. 2009). The results have been discordant among different countries since the relationship between SES and provider practice is not simple and affected by various elements, such as, the characteristics of healthcare systems. In Japan where healthcare is regarded as being quite generous and comprehensive (Ikegami 1991), no such associations have ever been demonstrated.

The aim of this study was to clarify whether and to what extent treatment of inpatients given by healthcare providers differs with respect to the SES of patient's residential area, by using the nationwide claims data of Japan. We simultaneously examined differences of treatments between hospitals with between neighborhoods by comparing macro-level variance.

\section{Materials and Methods}

Data source

The data were obtained from the Diagnosis Procedure Combination (DPC) database, a national administrative database launched in 2003 with case-mix classification for the use of acute inpatient medical care reimbursement. The DPC database codes all types of diseases and injuries using the International Classification of Diseases and Injuries 10th Revision (ICD-10) coding scheme. Details of the DPC data are provided elsewhere (Fushimi et al. 2007; Matsuda 2007). As of 2013, 52.9\% of all acute care hospitals are reimbursed through the DPC. More importantly, $86.8 \%$ of DPC beds are in hospitals with over 200 beds, (Ministry of Health Labor and Welfare Japan 2014) indicating that most patients with an acute condition are primarily treated at so-called "DPC hospitals". Meanwhile, the DPC has compiled patient postal code data since April 2011, enabling researchers to analyze geographical features of hospital care services. However, few research papers have utilized this geographical information (Iwamoto et al. 2015). In this study, we utilized 3-year DPC data from April 2011 to March 2013.

Ethical approval and consent to participate are not applicable.

\section{Main explanatory variables: patient residential areal SES}

We employed the Areal Deprivation Index (ADI) as a surrogate measure of patient residential areal SES. The ADI is defined as the weighted sum of eight Census indicators, as described below:

$$
\begin{aligned}
& A D I_{i}= k \times\left(2.99 \times \text { proportion of old couple household } s_{i}+\right. \\
& 7.57 \times \text { proportion of old single households } s_{i}+ \\
& 17.4 \times \text { proportion of single-mother households } s_{i}+ \\
& 2.22 \times \text { proportion of rental houses } \\
& 4.03 \times \text { proportion of sales and service } \text { workers }_{i}+ \\
& 6.05 \times \text { proportion of agricultural } \text { workers }_{i}+ \\
& 5.38 \times \text { proportion of blue collar } \text { workers }_{i}+ \\
& 18.3 \times \text { unemployment rate } \\
&+
\end{aligned}
$$

where $k$ is a positive constant and set to ' 1 ' in this study. The weights that reflect the relative importance of household poverty indicators were estimated by a micro-data analysis of households, according to previous works in Britain and other European countries (Dorling et al. 2007; Pornet et al. 2012). The deprivation index defined a 'poverty household' as a household of low socioeconomic position, both objectively and subjectively (Nakaya et al. 2014). Previous studies using the ADI identified socioeconomic inequalities in all-cause mortality (Nakaya et al. 2014) and cancer survival (Ito et al. 2014) in Osaka, Japan.

The ADI for this study was first determined for a small-area Census unit, or Cho-aza, as of 2010, and average values by postal area were calculated in a geographic information system (GIS). Thus, we estimated ADIs for all 113,291 postal areas (mean population density: 1,130 per area) across the country. We appended the ADI to each patient's DPC data to estimate their SES background. To promote intuitive understandings, we standardized ADI of the study samples where average value and standard deviation are set 0 and 1, respectively. Fig. 1 shows the distribution of the total study sample which shows the shape of normal distribution with maximum ADI; 10.36, and minimum; -4.03 .

\section{Target disease and outcome variables}

We selected all patients with a closed hip fracture (Closed fracture of neck of femur, Closed pertrochanteric fracture and Closed subtrochanteric fracture; ICD10 codes S72.00, S72.10 and S72.20, respectively). Although hip fracture is one of the most frequently encountered injuries in daily practice, because it is neither malignant nor emergency, treatment varies widely depending on patient characteristics and healthcare provider attitudes toward the injury. While practice varies, some recent guidelines and studies recommend early surgical intervention (Johansen et al. 2013; Nyholm et al. 2015).

Here, we adopted two different outcome variables to investigate gaps in healthcare providers' practice: (i) receipt of operation (i.e., not watching for spontaneous recovery), and (ii) number of days waiting for surgery following admission (a value of 0 was assigned if the operation was performed on the day of admission).

\section{Explanatory variables}

Analyses were adjusted for age group, sex, fracture type (Closed fracture of neck of femur, Closed pertrochanteric fracture, Closed subtrochanteric fracture), comorbidities, mental health, coma level, and ambulance use.

Patient comorbidity was a categorical variable with four groups: cancer, terminal organ failure, non-serious disease, and no comorbidity. The "cancer" group was flagged if patients had at least one malignant neoplasm (C00-D09) or one uncertain neoplasm (D37-48) as comorbidity, whereas the "terminal organ failure" group consisted of patients with more than one of the following five diagnosed organ failures: Hugh-Jones respiratory failure, classification IV or V; New 


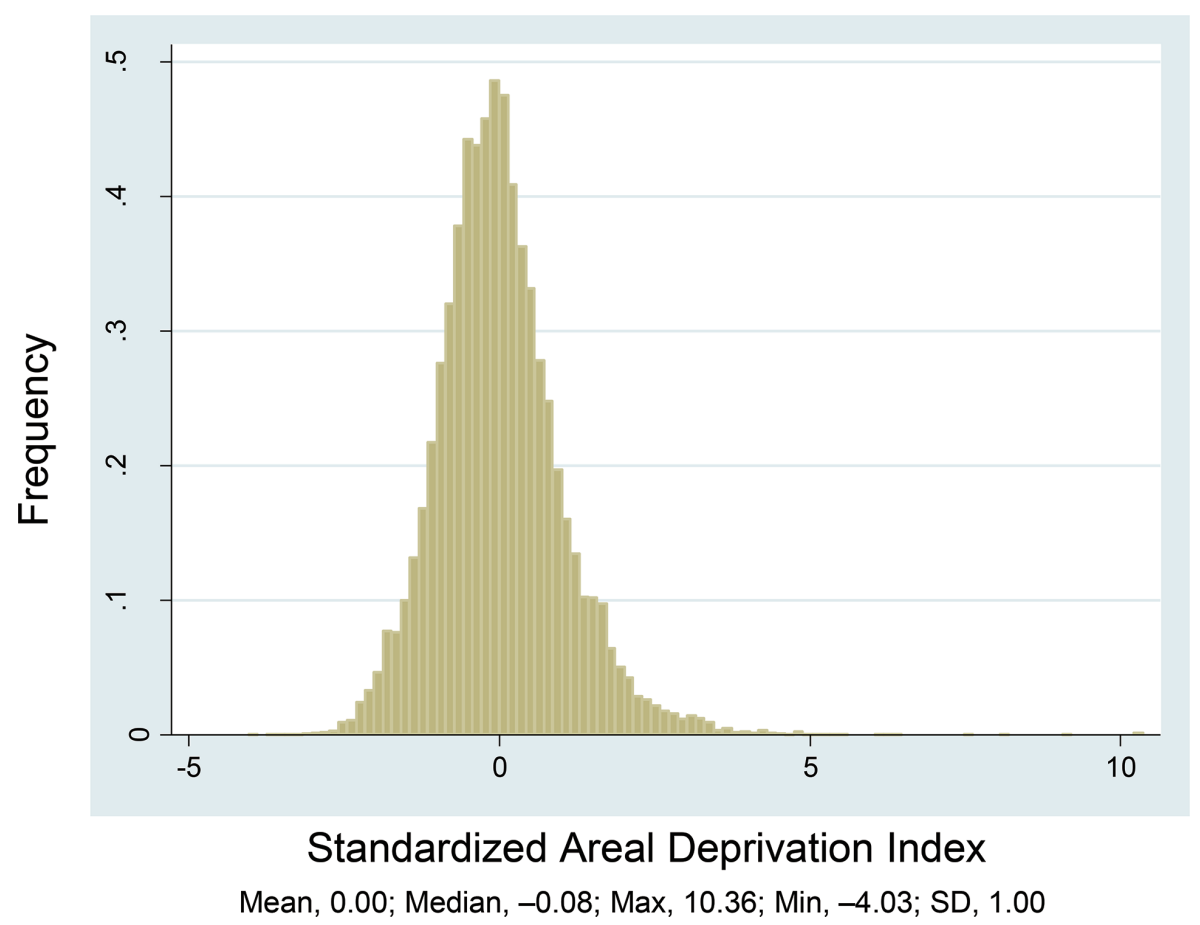

Fig. 1. Distribution of Areal Deprivation Index of total study sample $(\mathrm{n}=95,011)$.

The total study sample represented 95,011 patients (see Fig. 2). The vertical axis represents frequency of the value of Areal Deprivation Index (ADI). The horizontal axis represents each value of ADI which is standardized to have mean 0.00 and SD 1.00 .

York Heart Association functional classification III or IV; Canadian Cardiovascular Society grading of angina pectoris III or IV; ChildPugh class C; or end-stage renal failure (ICD10 code: N180). These categorized conditions are routinely filed in the DPC data along with ICD10 codes. If a patient had both cancer and organ failure as comorbidities, we included them in the cancer group. We categorized the patients' mental status into three groups: dementia (ICD10 codes: F00-03, G30), other mental diseases (F04*-09*), and no mental disease. The patients who were categorized under dementia or other mental diseases were diagnosed before their admission. If a patient had both dementia and another mental disease as comorbidities, we included them in the dementia group. The "coma level" was categorized into four consciousness depth levels using the Japan Coma Scale, which is routinely filed in DPC data. Details of the Japan Coma Scale are described elsewhere (Ohta et al. 1974; Shigemori et al. 2012). "Ambulance use" was flagged when patients were transported by ambulance to reach an acute hospital. The reason why ambulance use was selected as an explanatory variable is it can be a proxy of emergency, which can also affect time to surgery. All relevant ICD code names are shown in the Appendix 1.

\section{Exclusion criteria}

Two types of exclusion criteria were adopted: those related to deprivation (ADI-related), and those related to patients' physical characteristics.

First, we excluded all patients living in rural municipalities because the persistent issue of healthcare provider shortage in Japan would negatively affect healthcare services irrespective of the patients' residential areal SES or physical condition. Therefore, we excluded all patients living in cities and towns of less than 200,000 population, except for the three prefectural capital cities in this category, Tottori City, Yamaguchi City, and Yamanashi City. Also, municipalities in Tokyo Prefecture, except islands, were included because they contain wealthy urban areas (e.g., Musashino City, Kunitachi City, and Koganei City) that are likely to have adequate healthcare services even though they do not have more than 200,000 residents. In total, 316 cities or boroughs, which represented $52.5 \%$ of all domestic households, were included. In addition, due to the nature of the ADI formula, it is likely that ADIs have a wider variance and become statistically unstable when the number of households within the postal area is limited. This is because the eight census components of the ADI are all proportions or rates, which are prone to produce outliers with small sample sizes (Nakaya et al. 2014). Therefore, we excluded all patients living in postal areas where the number of households was less than 100 , even in urban cities.

Second, we attempted to balance patients baseline physical characteristics. For this purpose, we excluded all complicated cases from the target population, such as patients with coexisting severe trauma (e.g., brain bleeding), multiple fractures, and cases with dislocation, bilateral, comminuted, and recurrent hip fractures. Untypical cases, such as those of patients who died within 24 hours of admission, women who were pregnant or unsure, and suspected (unconfirmed) diagnosis cases, were also excluded. We also excluded all patients under 40 years old to remove congenital and juvenile cases, which would affect decisions by healthcare providers. The impact of these exclusions on our tested associations was subsequently assessed by sensitivity analyses.

\section{Statistical models}

We adopted cross-classified multilevel models (CCMMs) to 
disentangle three-level non-hierarchical-structure data where patients were cross-classified by hospital and neighborhood (i.e., postal areas), and where each patient has hospital and neighborhood profiles. Details of the CCMMs are described by Dunn et al. (2015), who showed that CCMM can modify overestimates of macro-level variance produced by traditional multilevel models in cases where data structure is cross-classified. All statistics were implemented using Bayesian Markov Chain Monte Carlo methods, combined with the iteratively generalized least squares estimates to make the data fit with a hierarchical structure, as a first step. Bayesian Markov Chain Monte Carlo model inputs in terms of the prior hyperparameters and test the robustness in that particular application. All results were computed using Stata 14.0 and MLwiN 2.30 software.

For the first receipt of operation analysis, we used a logistics model to obtain odds ratios (ORs) and 95\% credible intervals (CIs) for all applicable patients. Then, a linear regression model was applied to obtain coefficients and $95 \%$ credible intervals of waiting days for operation. The explanatory variables described previously were all set as compositional factors, whereas a patient's deprivation index (i.e., their residential areal SES) was a contextual factor. We ran three models for each analysis: 1) a null model, 2) a ADI-only model, and 3) a full model with clinical variables. Macro-level variance, which is usually calculated in regression models of multilevel analysis as the coefficients (or odds ratios) differ from each other at the macro level (in this study, hospital and neighborhood levels), is calculated for each model. Details of multilevel analysis including macro-level variance are described elsewhere (Kreft and De Leeuw 1998; Goldstein 2011). With the aim of testing the Wald statistic for macro-level variance, each Z-score (macro-level variance/standard deviation [SD]) was calculated to confirm its significance, where a Z-score $>2$ was regarded as $\mathrm{P}<0.05$ (Pagano and Gauvreau 2000).
Sensitivity analyses for the two steps of exclusion criteria were also conducted. First, we ran all models for patients with complicated clinical cases (i.e., without physical background-related exclusions). We then ran the analyses for all Japanese households (i.e. with ADIrelated exclusions) to confirm the robustness of our results.

\section{Availability of data and materials}

The Census dataset generated and analyzed during the current study are available in the Ministry of Internal Affairs and Communications, Japan repository, http://www.stat.go.jp/data/koku sei/2010/index.htm. The DPC dataset analyzed during the current study are not publicly available due to possible identification of personal information but are available from the corresponding author on reasonable request. Codes for CCMM are available in Dunn et al. (2015).

\section{Results}

Sample extraction and characteristics

From 198,509 patients with a closed hip fracture filed during the available period (April 2011-March 2013), 104,973 patients were extracted after ADI-related exclusions were applied. After exclusions for clinical background criteria, 95,011 patients from 1,050 hospitals and 21,643 postal areas were identified as the study population. A final 85,480 patients were included in the secondary analysis of waiting days for operation. The sample extraction process is summarized in Fig. 2.

Table 1 shows the baseline characteristics of the total study sample and those who received an operation. Females accounted for $78 \%$ of the study sample, and the

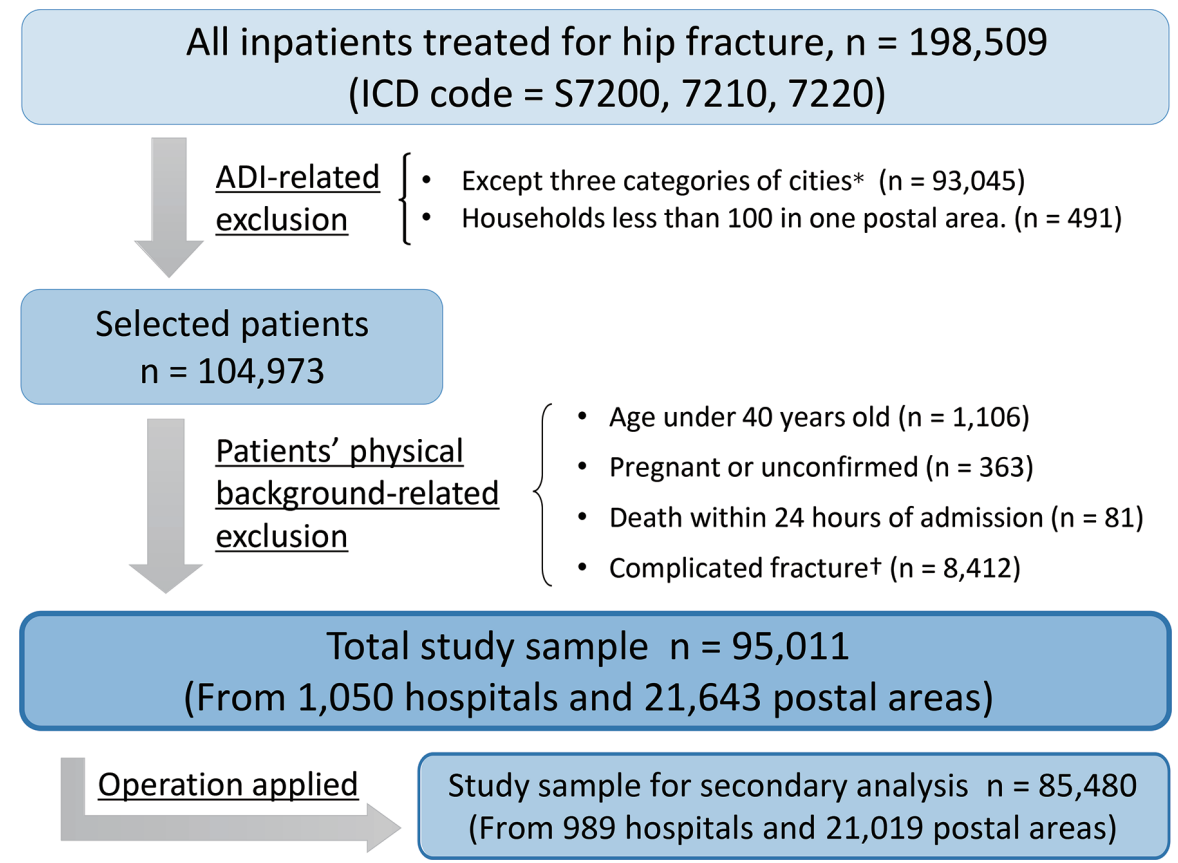

Fig. 2. Flow chart of the extraction of the study sample.

*Three categories of cities include metropolitan boroughs of three large economic zones (i.e., Tokyo, Nagoya, Osaka), cities more than 200,000 population and capital cities of 47 prefectures.

Complicated fracture includes bilateral or multiple hip fracture, fracture with dislocation, coexistence of severe trauma (e.g., brain bleeding), recurrent fracture and suspected (unconfirmed) cases. 
Table 1. Baseline characteristics of the study population, total and operation applied.

\begin{tabular}{|c|c|c|c|}
\hline & & $\begin{array}{c}\text { Total sample (\%) } \\
(n=95,011)\end{array}$ & $\begin{array}{c}\text { Operation applied (\%) } \\
(\mathrm{n}=85,480)\end{array}$ \\
\hline \multicolumn{4}{|l|}{ Sex } \\
\hline & Female & $74,406(78.3)$ & $67,179(78.6)$ \\
\hline \multicolumn{4}{|l|}{ Age Group } \\
\hline & $40-69$ & $10,911 \quad(11.5)$ & 9,839 (11.5) \\
\hline & $70-79$ & 21,959 (23.1) & $19,940 \quad(23.3)$ \\
\hline & $80-89$ & $43,313(45.6)$ & $39,123 \quad(45.8)$ \\
\hline & Over 90 & $18,828(19.8)$ & $16,578 \quad(19.4)$ \\
\hline \multicolumn{4}{|l|}{ Fructure Type } \\
\hline & Femoral neck & $54,249 \quad(57.1)$ & $49,313 \quad(57.7)$ \\
\hline & Trochanteric & $39,004 \quad(41.1)$ & $34,611 \quad(40.5)$ \\
\hline & Subtrochanteric & 1,758 (1.9) & $1,556(1.8)$ \\
\hline \multicolumn{4}{|l|}{ Complication } \\
\hline & No complication & $18,094(19.0)$ & $16,177 \quad(18.9)$ \\
\hline & Non-serious disease & $72,070 \quad(75.9)$ & $65,071 \quad(76.1)$ \\
\hline & Cancer & $3,500 \quad(3.7)$ & $3,050 \quad(3.6)$ \\
\hline & Terminal disease & $1,347 \quad(1.4)$ & $1,182 \quad(1.4)$ \\
\hline \multicolumn{4}{|l|}{ Mental Health } \\
\hline & No disease & $76,413 \quad(80.4)$ & $68,525(80.2)$ \\
\hline & Dementia & $12,242(12.9)$ & $11,083(13.0)$ \\
\hline & Other mental disease & $6,356 \quad(6.7)$ & $5,872(6.9)$ \\
\hline \multicolumn{4}{|l|}{ Coma Level* } \\
\hline & Alert & $84,892 \quad(89.3)$ & 76,609 (89.6) \\
\hline & Level 1 & $9,719(10.2)$ & $8,531(10.0)$ \\
\hline & Level 2 & $353(0.4)$ & $308(0.4)$ \\
\hline & Level 3 & $47(0.05)$ & $32(0.04)$ \\
\hline \multicolumn{4}{|l|}{ Ambulance use } \\
\hline & No ambulance use & $46,271 \quad(48.7)$ & $40,891 \quad(47.8)$ \\
\hline & Ambulance use & $48,740 \quad(51.3)$ & $44,589 \quad(52.2)$ \\
\hline
\end{tabular}

*Coma level refers to the Japan Coma Scale (JCS) which has four decisive levels of consciousness.

most common age group was $80-89$ years. For the 85,480 patients who received an operation, the mean (SD) number of waiting days was 4.24 (3.92) days, with a median of 3 days.

\section{Receipt of operation}

The results for use of operation are shown in Table 2. A majority of compositional factors affected operations with statistical significance, except age groups 70-79 and 80-89. The ORs of the ADI did not reach statistical significance $(\mathrm{P}=0.11)$. The ORs of the chance of receiving an operation were higher in patients with dementia (OR 1.22; $95 \%$ CI, 1.14, 1.31) and other mental diseases (OR 1.39; $95 \% \mathrm{CI}, 1.25,1.53)$ than in those without mental disorders, while patients with deeper coma levels were less likely to receive an operation. Fracture type was also an important factor for receipt of operation, with lower ORs observed for trochanteric (Coef, $0.74 ; 95 \%$ CI, 0.70, 0.77) and subtrochanteric fractures (Coef, 0.70; 95\% CI, 0.60, 0.83). Macro-level variances between hospitals and between postal areas in the full model were 1.23 and 0.05 , respectively, and their respective Z-scores were 14.80 and 6.07, indicating statistical significance.
Waiting days for operation

In the models shown in Table 3, almost all explanatory variables were more statistically significant for waiting days for an operation than those in the receipt of operation analysis. In particular, the ADI in the full model (Coef, 0.03, $95 \% \mathrm{CI},-0.01,0.06, \mathrm{P}=0.08$ ) was of note because it was not statistically significant in receipt of operation analysis. With respect to mental health comorbidities, having either dementia (Coef, $-0.28 ; 95 \% \mathrm{CI},-0.36,-0.21$ ) or other mental diseases (Coef, -0.26 ; 95\% CI, $-0.35,-0.16$ ) shortened the number of waiting days. Deeper coma levels incrementally lengthened the number of waiting days; coefficients of coma level 3 and 1 were 1.59 (95\% CI, 0.36, $2.80)$ and 0.13 (95\% CI, 0.05, 0.22), respectively. Macrolevel variances between hospitals and postal areas for the full model were 3.06 and 0.04 , and their Z-scores were 18.11 and 2.75 , respectively, both of which were statistically significant.

\section{Sensitivity analysis}

The first sensitivity analysis was conducted by including patients who were excluded from the primary analysis due to physical-background-related reasons $(n=104,973)$. 
Table 2. Multivariate-adjusted odds ratios and $95 \%$ CIs for application of operation with macro-level variance.

\begin{tabular}{|c|c|c|c|c|c|c|c|c|c|c|}
\hline \multirow[t]{2}{*}{$\mathrm{n}=95,011$} & & \multirow[t]{2}{*}{ model 1 (null) } & \multicolumn{4}{|c|}{ model 2 (ADI only) } & \multicolumn{4}{|c|}{ model 3 (with clinical variables) } \\
\hline & & & \multirow{3}{*}{$\begin{array}{c}\text { OR } \\
0.99\end{array}$} & \multicolumn{2}{|c|}{ 95\% Credible Int. } & \multirow{2}{*}{ P value } & \multirow{3}{*}{$\begin{array}{c}\text { OR } \\
0.99\end{array}$} & \multicolumn{2}{|c|}{ 95\% Credible Int. } & \multirow{2}{*}{ P value } \\
\hline \multirow{2}{*}{\multicolumn{3}{|c|}{$\begin{array}{l}\text { Contextual factor } \\
\qquad \text { Areal Deprivation Index }\end{array}$}} & & & & & & & & \\
\hline & & & & 0.96 & 1.02 & 0.16 & & 0.96 & 1.02 & 0.15 \\
\hline \multicolumn{11}{|c|}{ Compositional factor } \\
\hline \multirow[t]{2}{*}{ Sex } & Male (reference) & & & & & & & & & \\
\hline & Female & & & & & & 1.21 & 1.15 & 1.28 & $<0.001$ \\
\hline \multirow[t]{4}{*}{ Age Group } & $40-69$ (ref.) & & & & & & & & & \\
\hline & $70-79$ & & & & & & 1.05 & 0.97 & 1.14 & 0.13 \\
\hline & $80-89$ & & & & & & 0.97 & 0.90 & 1.05 & 0.20 \\
\hline & Over 90 & & & & & & 0.74 & 0.68 & 0.80 & $<0.001$ \\
\hline \multirow[t]{3}{*}{ Fx. Type } & Femoral neck (ref.) & & & & & & & & & \\
\hline & Trochanteric & & & & & & 0.74 & 0.71 & 0.78 & $<0.001$ \\
\hline & Subtrochanteric & & & & & & 0.70 & 0.60 & 0.82 & $<0.001$ \\
\hline \multirow[t]{4}{*}{ Complication } & No complication (ref.) & & & & & & & & & \\
\hline & Non-serious disease & & & & & & 1.21 & 1.13 & 1.28 & $<0.001$ \\
\hline & Cancer & & & & & & 0.89 & 0.79 & 1.00 & 0.03 \\
\hline & Terminal disease & & & & & & 0.84 & 0.70 & 1.01 & 0.03 \\
\hline \multirow[t]{3}{*}{ Mental Health } & No disease (ref.) & & & & & & & & & \\
\hline & Dementia & & & & & & 1.22 & 1.13 & 1.31 & $<0.001$ \\
\hline & Other mental disease & & & & & & 1.39 & 1.25 & 1.54 & $<0.001$ \\
\hline \multirow[t]{4}{*}{ Coma Level* } & Alert (ref.) & & & & & & & & & \\
\hline & Level 1 & & & & & & 0.80 & 0.74 & 0.86 & $<0.001$ \\
\hline & Level 2 & & & & & & 0.68 & 0.49 & 0.94 & 0.01 \\
\hline & Level 3 & & & & & & 0.26 & 0.13 & 0.51 & $<0.001$ \\
\hline \multicolumn{11}{|c|}{ Ambulance use No ambulance use (ref.) } \\
\hline & Ambulance use & & & & & & 1.31 & 1.24 & 1.37 & $<0.001$ \\
\hline \multicolumn{11}{|c|}{ Macro-level variance (S.D) } \\
\hline \multirow{2}{*}{\multicolumn{2}{|c|}{$\begin{array}{l}\text { between Hospitals }(n=1,050) \\
\text { between Postal Areas }(n=21,643)\end{array}$}} & $1.22 \quad(0.08)$ & 1.22 & $(0.08)$ & & & 1.22 & $(0.08)$ & & \\
\hline & & $0.03 \quad(0.00)$ & 0.04 & $(0.01)$ & & & 0.03 & $(0.01)$ & & \\
\hline
\end{tabular}

*Coma level refers to the Japan Coma Scale (JCS) which has four decisive levels of consciousness.

Table 3. Multivariate-adjusted coefficients and $95 \%$ CIs for waiting days for operation with macro-level variance.

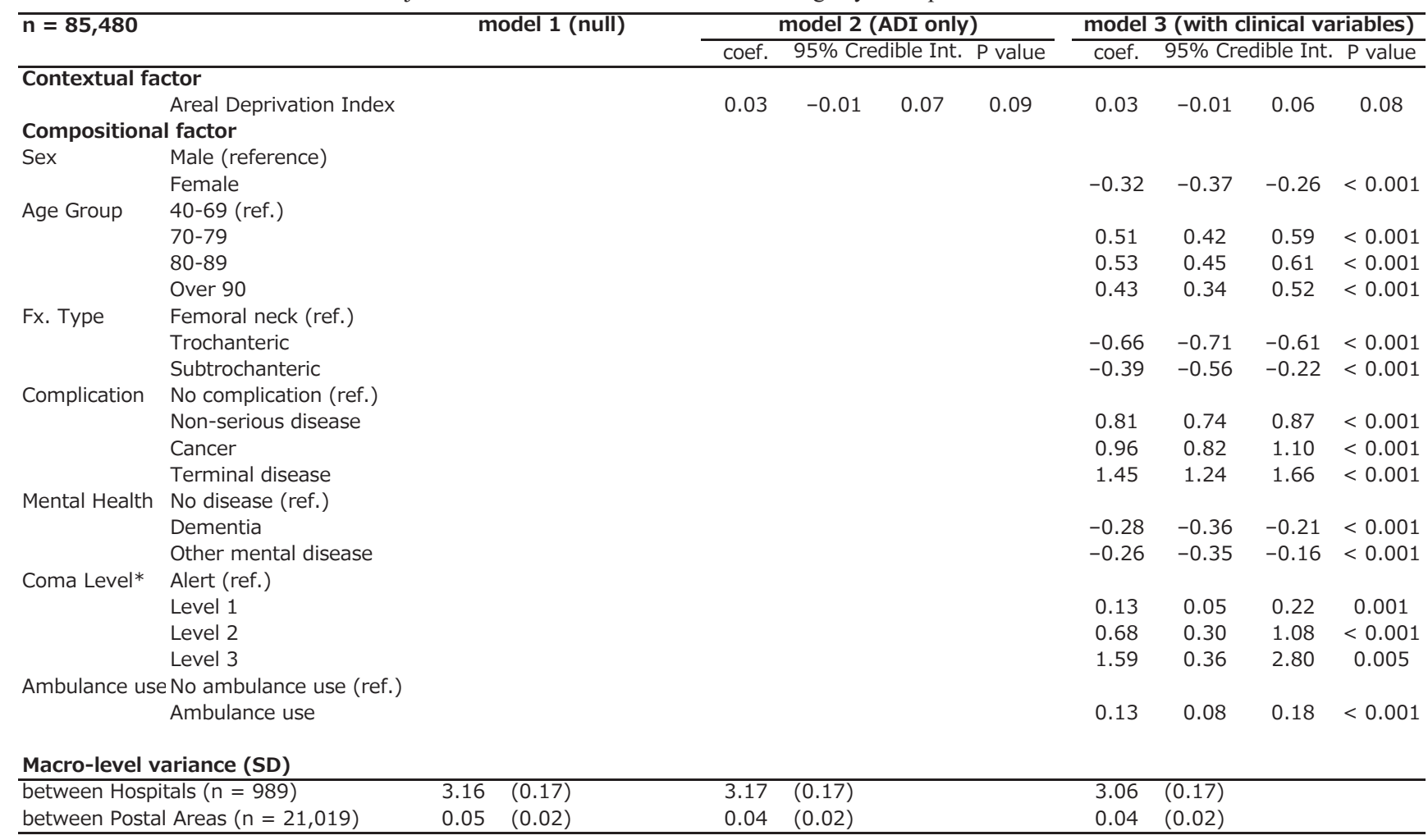

*Coma level refers to the Japan Coma Scale (JCS) which has four decisive levels of consciousness. 
Table 4. Sensitivity analysis 1a: Multivariate-adjusted odds ratios and 95\% CIs for application of operation with complicated physical background patients.

\begin{tabular}{|c|c|c|c|c|c|c|c|c|c|c|}
\hline \multirow[t]{2}{*}{$\mathrm{n}=104,973$} & & \multirow[t]{4}{*}{ model 1 (null) } & \multicolumn{4}{|c|}{ model 2 (ADI only) } & \multicolumn{4}{|c|}{ model 3 (with clinical variables) } \\
\hline & & & \multirow{3}{*}{$\begin{array}{c}\text { OR } \\
0.98\end{array}$} & \multicolumn{2}{|c|}{$95 \%$ Credible Int. } & \multirow[t]{2}{*}{$P$ value } & \multirow{3}{*}{$\begin{array}{c}\text { OR } \\
0.99\end{array}$} & \multicolumn{2}{|c|}{$95 \%$ Credible Int. } & \multirow{2}{*}{ P value } \\
\hline \multirow{2}{*}{\multicolumn{2}{|c|}{$\begin{array}{l}\text { Contextual factor } \\
\text { Areal Deprivation Index }\end{array}$}} & & & & & & & & & \\
\hline & & & & 0.96 & 1.01 & 0.15 & & 0.97 & 1.01 & 0.19 \\
\hline \multicolumn{11}{|c|}{ Compositional factor } \\
\hline \multirow[t]{2}{*}{ Sex } & Male (reference) & & & & & & & & & \\
\hline & Female & & & & & & 1.26 & 1.20 & 1.33 & $<0.001$ \\
\hline \multirow[t]{4}{*}{ Age Group } & $40-69$ (ref.) & & & & & & & & & \\
\hline & $70-79$ & & & & & & 1.45 & 1.35 & 1.56 & $<0.001$ \\
\hline & $80-89$ & & & & & & 1.37 & 1.28 & 1.46 & $<0.001$ \\
\hline & Over 90 & & & & & & 1.05 & 0.98 & 1.13 & 0.09 \\
\hline \multirow[t]{3}{*}{ Fx. Type } & Femoral neck (ref.) & & & & & & & & & \\
\hline & Trochanteric & & & & & & 0.82 & 0.78 & 0.86 & $<0.001$ \\
\hline & Subtrochanteric & & & & & & 0.73 & 0.64 & 0.84 & $<0.001$ \\
\hline \multirow[t]{4}{*}{ Complication } & No complication (ref.) & & & & & & & & & \\
\hline & Non-serious disease & & & & & & 1.30 & 1.23 & 1.38 & $<0.001$ \\
\hline & Cancer & & & & & & 1.11 & 1.00 & 1.23 & 0.02 \\
\hline & Terminal disease & & & & & & 1.09 & 0.90 & 1.30 & 0.19 \\
\hline \multirow[t]{3}{*}{ Mental Health } & No disease (ref.) & & & & & & & & & \\
\hline & Dementia & & & & & & 1.24 & 1.15 & 1.33 & $<0.001$ \\
\hline & Other mental disease & & & & & & 1.38 & 1.26 & 1.52 & $<0.001$ \\
\hline \multirow[t]{4}{*}{ Coma Level* } & Alert (ref.) & & & & & & & & & \\
\hline & Level 1 & & & & & & 0.83 & 0.77 & 0.90 & $<0.001$ \\
\hline & Level 2 & & & & & & 0.73 & 0.53 & 1.00 & 0.03 \\
\hline & Level 3 & & & & & & 0.35 & 0.18 & & $<0.001$ \\
\hline \multicolumn{11}{|c|}{ Ambulance us $\in$ No ambulance use (ref.) } \\
\hline & Ambulance use & & & & & & 1.46 & 1.40 & 1.52 & $<0.001$ \\
\hline \multicolumn{11}{|c|}{ Macro-level variance (SD) } \\
\hline \multicolumn{2}{|c|}{ between Hospitals $(n=1,062)$} & $1.18(0.08)$ & 1.18 & $(0.08)$ & & & 1.16 & $(0.07)$ & & \\
\hline between Post & | Areas $(n=22,329)$ & $0.02 \quad(0.01)$ & 0.02 & $(0.00)$ & & & 0.03 & $(0.01)$ & & \\
\hline
\end{tabular}

*Coma level refers to the Japan Coma Scale (JCS) which has four decisive levels of consciousness.

Table 5. Sensitivity analysis 1b: Multivariate-adjusted coefficients and $95 \%$ CIs for waiting days for operation including complicated physical background patients.

\begin{tabular}{|c|c|c|c|c|c|c|c|c|c|c|}
\hline \multicolumn{2}{|l|}{$n=93,530$} & \multirow[t]{4}{*}{ model 1 (null) } & \multicolumn{4}{|c|}{ model 2 (ADI only) } & \multicolumn{4}{|c|}{ model 3 (with clinical variables) } \\
\hline & & & \multirow{3}{*}{$\begin{array}{l}\text { coef. } \\
0.04\end{array}$} & \multicolumn{2}{|c|}{ 95\% Credible Int. } & \multirow[t]{2}{*}{ P value } & \multirow{3}{*}{$\begin{array}{c}\text { coef. } \\
0.04\end{array}$} & \multicolumn{2}{|c|}{ 95\% Credible Int. } & \multirow[t]{2}{*}{$\mathrm{P}$ value } \\
\hline \multirow{2}{*}{\multicolumn{2}{|c|}{$\begin{array}{l}\text { Contextual factor } \\
\quad \text { Areal Deprivation Index }\end{array}$}} & & & & & & & & & \\
\hline & & & & 0.00 & 0.09 & 0.03 & & 0.00 & 0.09 & 0.04 \\
\hline \multicolumn{11}{|c|}{ Compositional factor } \\
\hline \multirow[t]{2}{*}{ Sex } & Male (reference) & & & & & & & & & \\
\hline & Female & & & & & & -0.36 & -0.43 & -0.29 & $<0.001$ \\
\hline \multirow[t]{4}{*}{ Age Group } & 40-69 (ref.) & & & & & & & & & \\
\hline & $70-79$ & & & & & & 0.56 & 0.46 & 0.65 & $<0.001$ \\
\hline & $80-89$ & & & & & & 0.61 & 0.51 & 0.70 & $<0.001$ \\
\hline & Over 90 & & & & & & 0.47 & 0.37 & 0.58 & $<0.001$ \\
\hline \multirow[t]{3}{*}{ Fx. Type } & Femoral neck (ref.) & & & & & & & & & \\
\hline & Trochanteric & & & & & & -0.66 & -0.72 & -0.60 & $<0.001$ \\
\hline & Subtrochanteric & & & & & & -0.38 & -0.58 & -0.19 & $<0.001$ \\
\hline \multirow[t]{4}{*}{ Complication } & No complication (ref.) & & & & & & & & & \\
\hline & Non-serious disease & & & & & & 0.87 & 0.79 & 0.95 & $<0.001$ \\
\hline & Cancer & & & & & & 1.04 & 0.89 & 1.19 & $<0.001$ \\
\hline & Terminal disease & & & & & & 1.64 & 1.39 & 1.87 & $<0.001$ \\
\hline \multirow[t]{3}{*}{ Mental Health } & No disease (ref.) & & & & & & & & & \\
\hline & Dementia & & & & & & -0.30 & -0.39 & -0.21 & $<0.001$ \\
\hline & Other mental disease & & & & & & -0.25 & -0.37 & -0.14 & $<0.001$ \\
\hline \multirow[t]{4}{*}{ Coma Level* } & Alert (ref.) & & & & & & & & & \\
\hline & Level 1 & & & & & & 0.12 & 0.02 & 0.22 & 0.01 \\
\hline & Level 2 & & & & & & 0.66 & 0.21 & 1.10 & 0.003 \\
\hline & Level 3 & & & & & & 1.22 & -0.10 & 2.54 & 0.04 \\
\hline \multicolumn{11}{|c|}{ Ambulance us $\in$ No ambulance use (ref.) } \\
\hline & Ambulance use & & & & & & 0.10 & 0.04 & 0.16 & $<0.001$ \\
\hline \multicolumn{11}{|c|}{ Macro-level variance (SD) } \\
\hline \multirow{2}{*}{\multicolumn{2}{|c|}{$\begin{array}{l}\text { between Hospitals }(n=998) \\
\text { between Postal Areas }(n=21,697)\end{array}$}} & $6.66 \quad(0.38)$ & 6.68 & $(0.38)$ & & & 6.55 & $(0.37)$ & & \\
\hline & & $0.14 \quad(0.05)$ & 0.15 & $(0.03)$ & & & 0.15 & $(0.03)$ & & \\
\hline
\end{tabular}

*Coma level refers to the Japan Coma Scale (JCS) which has four decisive levels of consciousness. 
Table 6. Sensitivity analysis 2a: Multivariate-adjusted ORs and 95\% CIs for application of operation with all data including ADI related exclusions.

\begin{tabular}{|c|c|c|c|c|c|c|c|c|c|c|}
\hline \multicolumn{2}{|l|}{$\mathrm{n}=198,509$} & \multirow[t]{4}{*}{ model 1 (null) } & \multicolumn{4}{|c|}{ model 2 (ADI only) } & \multicolumn{4}{|c|}{ model 3 (with clinical variables) } \\
\hline & & & \multirow{3}{*}{$\begin{array}{c}\text { OR } \\
1.00\end{array}$} & \multicolumn{2}{|c|}{ 95\% Credible Int. } & \multirow[t]{2}{*}{$\mathrm{P}$ value } & \multirow[t]{2}{*}{ OR } & \multicolumn{2}{|c|}{ 95\% Credible Int. } & \multirow{2}{*}{ P value } \\
\hline \multicolumn{6}{|c|}{ Contextual factor } & & & & & \\
\hline & Areal Deprivation Index & & & 0.98 & 1.02 & 0.39 & 0.99 & 0.97 & 1.01 & 0.08 \\
\hline \multicolumn{11}{|c|}{ Compositional factor } \\
\hline \multirow[t]{2}{*}{ Sex } & Male (reference) & & & & & & & & & \\
\hline & Female & & & & & & 1.32 & 1.27 & 1.38 & $<0.001$ \\
\hline \multirow[t]{4}{*}{ Age Group } & 40-69 (ref.) & & & & & & & & & \\
\hline & 70-79 & & & & & & 1.46 & 1.39 & 1.53 & $<0.001$ \\
\hline & $80-89$ & & & & & & 1.35 & 1.29 & 1.42 & $<0.001$ \\
\hline & Over 90 & & & & & & 1.05 & 1.00 & 1.11 & 0.03 \\
\hline \multirow{3}{*}{ Fx. Type } & Femoral neck (ref.) & & & & & & & & & \\
\hline & Trochanteric & & & & & & 0.85 & 0.82 & 0.88 & $<0.001$ \\
\hline & Subtrochanteric & & & & & & 0.71 & 0.64 & 0.78 & $<0.001$ \\
\hline \multirow[t]{4}{*}{ Complication } & No complication (ref.) & & & & & & & & & \\
\hline & Non-serious disease & & & & & & 1.25 & 1.20 & 1.30 & $<0.001$ \\
\hline & Cancer & & & & & & 1.09 & 1.01 & 1.18 & 0.02 \\
\hline & Terminal disease & & & & & & 0.99 & 0.88 & 1.13 & 0.43 \\
\hline \multirow[t]{3}{*}{ Mental Health } & No disease (ref.) & & & & & & & & & \\
\hline & Dementia & & & & & & 1.23 & 1.17 & 1.30 & $<0.001$ \\
\hline & Other mental disease & & & & & & 1.40 & 1.31 & 1.50 & $<0.001$ \\
\hline \multirow[t]{4}{*}{ Coma Level* } & Alert (ref.) & & & & & & & & & \\
\hline & Level 1 & & & & & & 0.83 & 0.79 & 0.87 & $<0.001$ \\
\hline & Level 2 & & & & & & 0.64 & 0.52 & 0.79 & $<0.001$ \\
\hline & Level 3 & & & & & & 0.29 & 0.17 & 0.45 & $<0.001$ \\
\hline \multicolumn{11}{|c|}{ Ambulance us $\in$ No ambulance use (ref.) } \\
\hline & Ambulance use & & & & & & 1.54 & 1.49 & 1.59 & $<0.001$ \\
\hline \multicolumn{11}{|c|}{ Macro-level variance (SD) } \\
\hline \multirow{2}{*}{\multicolumn{2}{|c|}{$\begin{array}{l}\text { between Hospitals }(n=1,163) \\
\text { between Postal Areas }(n=52,921)\end{array}$}} & $\begin{array}{ll}1.59 & (0.09)\end{array}$ & 1.58 & $(0.08)$ & & & 1.54 & $(0.08)$ & & \\
\hline & & $0.04 \quad(0.00)$ & 0.04 & $(0.01)$ & & & 0.04 & $(0.01)$ & & \\
\hline
\end{tabular}

*Coma level refers to the Japan Coma Scale (JCS) which has four decisive levels of consciousness.

Table 7. Sensitivity analysis $2 \mathrm{~b}$ : Multivariate-adjusted coefficients and $95 \%$ CIs for waiting days for operation with all data including ADI related exclusions.

\begin{tabular}{|c|c|c|c|c|c|c|c|c|c|c|}
\hline \multicolumn{2}{|l|}{$\mathrm{n}=176,881$} & \multirow[t]{2}{*}{ model 1 (null) } & \multicolumn{4}{|c|}{ model 2 (ADI only) } & \multicolumn{4}{|c|}{ model 3 (with clinical variables) } \\
\hline & & & \multirow{3}{*}{$\begin{array}{l}\text { coef. } \\
0.03\end{array}$} & \multicolumn{2}{|c|}{ 95\% Credible Int. } & \multirow[t]{2}{*}{$\mathrm{P}$ value } & \multirow[t]{2}{*}{ coef. } & \multicolumn{2}{|c|}{ 95\% Credible Int. } & \multirow[t]{2}{*}{ P value } \\
\hline \multicolumn{3}{|c|}{ Contextual factor } & & & & & & & & \\
\hline & Areal Deprivation Index & & & -0.01 & 0.06 & 0.07 & 0.02 & -0.01 & 0.06 & 0.11 \\
\hline \multicolumn{11}{|c|}{ Compositional factor } \\
\hline \multirow[t]{2}{*}{ Sex } & Male (reference) & & & & & & & & & \\
\hline & Female & & & & & & -0.34 & -0.40 & -0.29 & $<0.001$ \\
\hline \multirow[t]{4}{*}{ Age Group } & 40-69 (ref.) & & & & & & & & & \\
\hline & $70-79$ & & & & & & 0.52 & 0.45 & 0.60 & $<0.001$ \\
\hline & $80-89$ & & & & & & 0.55 & 0.47 & 0.62 & $<0.001$ \\
\hline & Over 90 & & & & & & 0.40 & 0.31 & 0.48 & $<0.001$ \\
\hline \multirow[t]{3}{*}{ Fx. Type } & Femoral neck (ref.) & & & & & & & & & \\
\hline & Trochanteric & & & & & & -0.68 & -0.73 & -0.63 & $<0.001$ \\
\hline & Subtrochanteric & & & & & & -0.42 & -0.56 & -0.27 & $<0.001$ \\
\hline \multirow[t]{4}{*}{ Complication } & No complication (ref.) & & & & & & & & & \\
\hline & Non-serious disease & & & & & & 0.90 & 0.84 & 0.96 & $<0.001$ \\
\hline & Cancer & & & & & & 1.11 & 0.99 & 1.22 & $<0.001$ \\
\hline & Terminal disease & & & & & & 1.82 & 1.62 & 2.01 & $<0.001$ \\
\hline \multirow[t]{3}{*}{ Mental Health } & No disease (ref.) & & & & & & & & & \\
\hline & Dementia & & & & & & -0.27 & -0.33 & -0.20 & $<0.001$ \\
\hline & Other mental disease & & & & & & -0.15 & -0.24 & -0.07 & $<0.001$ \\
\hline \multirow[t]{4}{*}{ Coma Level* } & Alert (ref.) & & & & & & & & & \\
\hline & Level 1 & & & & & & 0.12 & 0.04 & 0.20 & 0.001 \\
\hline & Level 2 & & & & & & 0.54 & 0.18 & 0.89 & 0.002 \\
\hline & Level 3 & & & & & & 1.43 & 0.33 & 2.51 & 0.004 \\
\hline \multicolumn{11}{|c|}{ Ambulance us $€$ No ambulance use (ref.) } \\
\hline & Ambulance use & & & & & & 0.10 & 0.06 & 0.15 & $<0.001$ \\
\hline \multicolumn{11}{|c|}{ Macro-level variance (SD) } \\
\hline \multirow{2}{*}{\multicolumn{2}{|c|}{$\begin{array}{l}\text { between Hospitals }(n=1,087) \\
\text { between Postal Areas }(n=50,825)\end{array}$}} & $3.34 \quad(0.16)$ & 3.35 & $(0.16)$ & & & 3.27 & $(0.15)$ & & \\
\hline & & $0.15 \quad(0.03)$ & 0.12 & $(0.04)$ & & & 0.16 & $(0.03)$ & & \\
\hline
\end{tabular}

*Coma level refers to the Japan Coma Scale (JCS) which has four decisive levels of consciousness. 
For the operation analysis (Table 4), we likewise found that the ADI was not statistically significant in the full model (OR $0.98 ; 95 \%$ CI, 0.96, 1.01). In contrast, for the analysis of waiting days (Table 5), the ADI was statistically significant (Coef, 0.04; 95\% CI, 0.00, 0.07; $\mathrm{P}=0.04$ ).

The second sensitivity analysis $(n=198,509)$ included data from all closed hip fracture patients irrespective of any exclusion criteria (i.e., patients excluded for their physical background and patients excluded for living in rural areas). For the operation analysis (Table 6), the ADI was not statistically significant (OR 0.99; 95\% CI, 0.97, 1.01; P = 0.19); likewise, for the analysis of waiting days (Table 7), the ADI did not reach statistical significance (OR $0.02 ; 95 \%$ CI, $-0.01,0.05, \mathrm{P}=0.11$ ).

\section{Discussion}

This study used nationwide hospital claims data to investigate whether healthcare providers working in hospitals provide different treatments to inpatients living in different SES areas. The results have several important implications: living in different SES (i.e., ADI) areas was not associated with differences in receipt of operation for hip fracture, but patients of lower SES (i.e., higher ADI) experienced slightly longer waiting times (days) before they receive operation. Assuming, the p-value still indicates statistically significant, with a coefficient of 0.027 , the gap in waiting days between patients with maximum ADI (10.36) and minimum ADI $(-4.03)$ across the country was only 0.39 days. We therefore conclude that patient residential SES has an extremely small impact on the number of waiting days for an operation. Sensitivity analyses indicate the tendency is equally applicable with all the patients excluded for physical background reason. However, if we add patients in rural areas, deprivation index does not have statistical significance any more for waiting days analysis.

Macro-level variance between hospitals was considerably larger than that for postal areas in all analyses and models. Since changes in macro-level variance among models were significant only between models 2 and 3 in the analysis of waiting days between hospitals, we expect that clinical conditions are the only factor that can account for these differences. These results indicate that unequal practice is not associated with neighborhood of residence but with different hospitals, particularly with regard to differences in waiting days for operation. Policy measures or appropriate guidelines are required to diminish this inequality of practice among hospitals.

The present study has three main strengths. First, we scrutinized healthcare provider practices towards patients, rather than assessing health outcomes, using large-scale nationwide claims data. Provided that financial risk protection has been a large concern of universal health coverage even for countries where access to healthcare is widely granted (Saksena et al. 2014), and there are little evidence of providing adequate financial protection in most countries, the value of this study is elucidating there is almost no problem of financial risk even for vulnerable population in Japanese healthcare system setting.

Second, to estimate SES, we used a postal-level SES indicator rather than the conventional regional-level ones (e.g., municipality), which is often substituted by a broader index, such as the Gini coefficient or regional GDP (Borges et al. 2016; Moeller and Quiñonez 2016). As we previously described, due to its homogeneity, geographical disparity of SES in Japan is not as obvious as in other countries, however, there are several articles arguing it is existing especially in metropolitan areas, such as Tokyo or Kyoto (Kurasawa 1986; Fielding 2004). This present study is adding a new evidence confirming there are almost no relationships between SES of patients living area and hospital practice in Japan.

Third, by employing CCMMs, which have been developed over the past few decades (Goldstein 1986, 1994; Rasbash and Browne 2008) but have not been applied to health service analysis, we could simultaneously examine non-hierarchical hospital-level and neighborhood-level effects. It is favorable to examine both effects simultaneously in a healthcare system where so-called "free access" is permitted to patients because treatments are often conducted at hospitals that are unrelated to their living areas. None of the previous studies of this kind utilized CCMM but instead employed traditional models, such as multivariate logistics, linear regression, or multilevel models, by setting an SES indicator as an explanatory variable (van Ryn and Burke 2000; Dy et al. 2016). However, as Dunn et al. (2015) argued, model fitness is questionable using those traditional models. Additionally, macro-level variance may not be as accurate as CCMM. We believe CCMMs will be beneficial for studies in countries like Japan, where patients are privileged to have cross-boundary access to healthcare facilities.

Several limitations of this study should be acknowledged. First, our study assessed only hip fractures and may thus not be generalizable to other diseases or injuries, such as prostate cancer, the treatment of which is often believed to reflect inequality. Second, in most cases, medical decisions are not made by individual providers, but are often made according to the patient's and their family's preferences. Therefore, patients may choose to opt out of receiving an operation following their own values.

This study has revealed that the SES of patient's residential area does not affect the decision to proceed with surgical treatment for hip fracture and has ignorable impact on waiting days from hospital admission to surgery in Japan. These results clearly indicate that patients in Japan do not receive differential treatment for hip fracture according to their area of residence. The rather larger macro-level variance between hospitals than that between neighborhoods indicates the considerable difference in treatments exists between hospitals. 


\section{Acknowledgments}

This study was supported by JSPS KAKENHI Grant Number $15 \mathrm{H} 02964$.

\section{Author Contributions}

S.T. and T.N. conducted the study in their respective sites; S.M. acquired the data; M.O. cleaned the data; S.T. analyzed the data and prepared the first draft of the manuscript; All authors commented on drafts and read and approved the final manuscript.

\section{Conflict of Interest}

The authors declare no conflict of interest.

\section{References}

Barone, A.P., Fusco, D., Colais, P., D’Ovidio, M., Belleudi, V., Agabiti, N., Sorge, C., Davoli, M. \& Perucci, C.A. (2009) Effects of socioeconomic position on 30-day mortality and wait for surgery after hip fracture. Int. J. Qual. Health Care, 21, 379-386.

Borges, M.C., Santos, L.P., Zago, A.M., da Silva, B.G., da Silva, S.G. \& de Mola, C.L. (2016) Socioeconomic development of cities and risk factors for non-communicable diseases: a comparative study across Brazilian state capitals. J. Public Health (Oxf), 38, 653-359.

Dorling, D., Rigby, J., Wheeler, B., Ballas, D., Thomas, B., Fahmy, E., Gordon, D. \& Lupton, R. (2007) Poverty, Wealth and Place in Britain, 1968 to 2005, The Policy Press for the Joseph Rowntree Foundation, Bristol, UK.

Dunn, E.C., Richmond, T.K., Milliren, C.E. \& Subramanian, S. (2015) Using cross-classified multilevel models to disentangle school and neighborhood effects: an example focusing on smoking behaviors among adolescents in the United States. Health Place, 31, 224-232.

Dy, C.J., Lane, J.M., Pan, T.J., Parks, M.L. \& Lyman, S. (2016) Racial and socioeconomic disparities in hip fracture care. $J$. Bone Joint Surg. Am., 98, 858-865.

Fanuele, J.C., Lurie, J.D., Zhou, W., Koval, K.J. \& Weinstein, J.N. (2009) Variation in hip fracture treatment: are black and white patients treated equally? Am. J. Orthop. (Belle Mead NJ), 38, E13-17.

Fielding, A.J. (2004) Class and space: social segregation in Japanese cities. Trans. Inst. Br. Geogr., 29, 64-84.

Fushimi, K., Hashimoto, H., Imanaka, Y., Kuwabara, K., Horiguchi, H., Ishikawa, K.B. \& Matsuda, S. (2007) Functional mapping of hospitals by diagnosis-dominant case-mix analysis. BMC Health Serv. Res., 7, 50.

Goldstein, H. (1986) Multilevel mixed linear model analysis using iterative generalized least squares. Biometrika, 73, 43-56.

Goldstein, H. (1994) Multilevel cross-classified models. Sociol. Methods Res., 22, 364-375.

Goldstein, H. (2011) Multilevel statistical models (Vol. 922), John Wiley \& Sons, London, UK.

Ikegami, N. (1991) Japanese health care: low cost through regulated fees. Health Aff., 10, 87-109.

Ito, Y., Nakaya, T., Nakayama, T., Miyashiro, I., Ioka, A., Tsukuma, H. \& Rachet, B. (2014) Socioeconomic inequalities in cancer survival: a population-based study of adult patients diagnosed in Osaka, Japan, during the period 1993-2004. Acta Oncol., 53, 1423-1433.

Iwamoto, T., Hashimoto, H., Horiguchi, H. \& Yasunaga, H. (2015) Effectiveness of hospital functions for acute ischemic stroke treatment on in-hospital mortality: results from a nationwide survey in Japan. J. Epidemiol., 25, 522-528.

Johansen, A., Wakeman, R., Boulton, C., Plant, F., Roberts, J. \&
Williams, A. (2013) National Hip Fracture Database: National Report 2013. Clinical Effectiveness and Evaluation Unit at the Royal College of Physicians.

https://www.nhfd.co.uk/20/hipfractureR.nsf/0/CA920122A24 4F2ED802579C900553993/\$file/NHFD\%20Report\%202013. pdf

[Accessed: May 30, 2018].

Kawachi, I., Kennedy, B.P., Lochner, K. \& Prothrow-Stith, D. (1997) Social capital, income inequality, and mortality. Am. J. Public Health, 87, 1491-1498.

Kondo, N., Sembajwe, G., Kawachi, I., van Dam, R.M., Subramanian, S.V. \& Yamagata, Z. (2009) Income inequality, mortality, and self rated health: meta-analysis of multilevel studies. $B M J$, 339, b4471.

Kreft, I.G. \& De Leeuw, J. (1998) Introducing multilevel modeling, SAGE Publications Ltd.

Kurasawa, S. (1986) Social Atlas of Tokyo, University of Tokyo Press, Japan.

Löfvendahl, S., Eckerlund, I., Hansagi, H., Malmqvist, B., Resch, S. \& Hanning, M. (2005) Waiting for orthopaedic surgery: factors associated with waiting times and patients' opinion. Int. J. Qual. Health Care, 17, 133-140.

Management and Coordination Agency (1995) Dowa-chiku general research report.

Matsuda, S. (2007) Casemix as a tool for transparency of medical services. Jpn. J. Soc. Secur. Policy, 6, 43-53.

Ministry of Health Labor and Welfare Japan (2014) The transition of DPC hospitals and beds.

https://www.mhlw.go.jp/file/06-Seisakujouhou-12400000Hokenkyoku/0000039616.pdf

[Accessed: February 10, 2019].

Moeller, J. \& Quiñonez, C. (2016) The association between income inequality and oral health in Canada: a cross-sectional study. Int. J. Health Serv., 46, 790-809.

Nakaya, T., Honjo, K., Hanibuchi, T., Ikeda, A., Iso, H., Inoue, M., Sawada, N. \& Tsugane, S.; Japan Public Health Center-based Prospective Study Group (2014) Associations of all-cause mortality with census-based neighbourhood deprivation and population density in Japan: a multilevel survival analysis. PLoS One, 9, e97802.

Nyholm, A.M., Gromov, K., Palm, H., Brix, M., Kallemose, T. \& Troelsen, A.; Danish Fracture Database Collaborators (2015) Time to surgery is associated with thirty-day and ninety-day mortality after proximal femoral fracture. J. Bone Joint Surg., 97, 1333-1339.

Organisation for Economic Co-operation and Development (OECD) (2017) Health at a Glance 2017. http://www.oecd.org/health/health-systems/health-at-a-glance19991312.htm [Accessed: May 5, 2018].

Ohta, T., Waga, S., Handa, W., Saito, I. \& Takeuchi, K. (1974) New grading of level of disordered consiousness (author's transl.). No Shinkei Geka, 2, 623-627.

Pagano, M. \& Gauvreau, K. (2000) Principles of biostatistics, Duxbury Pacific Grove, CA, pp. 176-184.

Pickett, K.E. \& Pearl, M. (2001) Multilevel analyses of neighbourhood socioeconomic context and health outcomes: a critical review. J. Epidemiol. Community Health, 55, 111-122.

Pornet, C., Delpierre, C., Dejardin, O., Grosclaude, P., Launay, L., Guittet, L., Lang, T. \& Launoy, G. (2012) Construction of an adaptable European transnational ecological deprivation index: the French version. J. Epidemiol. Community Health, 66, 982-989.

Saksena, P., Hsu, J. \& Evans, D.B. (2014) Financial risk protection and universal health coverage: evidence and measurement challenges. PLoS Med., 11, e1001701.

Shigemori, M., Abe, T., Aruga, T., Ogawa, T., Okudera, H., Ono, J., Onuma, T., Katayama, Y., Kawai, N., Kawamata, T., Kohmura, E., Sakaki, T., Sakamoto, T., Sasaki, T., Sato, A., et al. (2012) 
Guidelines for the Management of Severe Head Injury, 2nd Edition guidelines from the Guidelines Committee on the Management of Severe Head Injury, the Japan Society of Neurotraumatology. Neurol. Med. Chir. (Tokyo), 52, 1-30.

Shortt, S.E. \& Shaw, R.A. (2003) Equity in Canadian health care: does socioeconomic status affect waiting times for elective surgery? CMAJ, 168, 413-416.
United Nations (UN) (2017) Total international migrant stock. http://www.un.org/en/development/desa/population/migration/ index.asp

[Accessed: February 10, 2019].

van Ryn, M. \& Burke, J. (2000) The effect of patient race and socio-economic status on physicians' perceptions of patients. Soc. Sci. Med., 50, 813-828.

Appendix 1. Relevant ICD10 codes.

\begin{tabular}{lll}
\hline ICD10 code & Disease name & Variable name \\
\hline C00-D09 & Malignant neoplasms & Cancer \\
D37-48 & Uncertain neoplasms & Cancer \\
F00* & Dementia in Alzheimer's disease & Dementia \\
F01* & Vascular dementia & Dementia \\
F02* & Dementia in other diseases classified elsewhere & Dementia \\
F03* & Unspecified dementia & Dementia \\
F04* & Organic amnesic syndrome, not induced by alcohol and other psychoactive substances & Other mental illness \\
F05* & Delirium, not induced by alcohol and other psychoactive substances & Other mental illness \\
F06* & Other mental disorders due to brain damage and dysfunction and to physical disease & Other mental illness \\
F07* & Personality and behavioural disorders due to brain disease, damage and dysfunction & Other mental illness \\
F08* & N/A & Other mental illness \\
F09* & Unspecified organic or symptomatic mental disorder & Other mental illness \\
G30 & Alzheimer's disease & Dementia \\
N18.0 & End-stage renal disease & Terminal disease \\
S72.00 & Closed fracture of neck of femur & Femoral neck (ref.) \\
S72.10 & Closed pertrochanteric fracture & Trochanteric \\
S72.20 & Closed subtrochanteric fracture & Subtrochanteric \\
\hline
\end{tabular}

